\title{
REVIEW
}

\section{Developing a supportive peer environment: Engaging students through cooperative skills in the classroom}

\author{
John S. Saroyan \\ Pepperdine University, 24255 Pacific Coast Highway, Malibu, CA 90263, USA
}

\section{Check for updates}

Correspondence to: John S. Saroyan, Pepperdine University, 24255 Pacific Coast Highway, Malibu, CA 90263, USA;

E-mail: john.saroyan@pepperdine.edu

Received: March 3, 2021;

Accepted: March 30, 2021;

Published: April 1, 2021

Citation: Saroyan J.S. (2021). Developing a supportive peer environment: Engaging students through cooperative skills in the classroom. Advances in Developmental and Educational Psychology, 3(1): 81-89. https://doi.org/10.25082/ADEP.2021.01.001

Copyright: () 2021 John S. Saroyan. This is an open access article distributed under the terms of the Creative Commons Attribution License, which permits unrestricted use, distribution, and reproduction in any medium, provided the original author and source are credited.

\begin{abstract}
Children with peer acceptance problems struggle to fit in among classmates and often feel rejection and social isolation. Common reasons can stem from a child's unique personality, individuality or special needs issues. These children often experience emotional problems and symptoms resulting from poor social relationships and difficulty fitting in to their environment. Within the classroom, teachers may provide encouragement and support for these children as well as their better adjusted peers, helping them equally engage through improved understanding and acceptance. In this article, a cooperative classroom approach is discussed to help students develop healthier communication with mutual respect and the freedom to be their natural, core self. A Democratic Student Council is presented as a cooperative classroom activity that encourages peer compassion and openness while supporting individuality and feelings of belonging.
\end{abstract}

Keywords: social acceptance, bullying, core self, cooperative learning, student council, belonging

\section{Introduction}

Children with emotional difficulties can be identified through their behavior and affect. Some students with emotional/behavioral disabilities (EBD) or learning disabilities (LD) act out and draw in attention due to troubles experienced at school, home or other settings. Other students with an EBD or LD may present as quiet and isolative and not show obvious behavioral or emotional problems. Consequently, these students may be overlooked, thus perpetuating their feelings of neglect, rejection or feelings of not belonging. Teachers and school personnel often become aware of certain children struggling emotionally but have limited options to address their needs. Certainly a referral to the school psychologist or counselor may give notice to a particular student and provide them with individualized attention or initiate a student study team to explore meeting the student's needs.

Social rejection and peer isolation commonly occur when a child appears different or is not conforming to group norms (Cranham \& Carroll, 2003). Victimization from peers may also be present because of uniqueness and individuality (MacDonald \& Swart, 2004). These children may experience low self esteem, loneliness, depression, anxiety, absenteeism and academic difficulties with serious long-term effects (Smokowski \& Kopasz, 2005). They may also present as quiet, cautious, insecure and sensitive with troubles in problem solving skills and communication (Glew et al., 2000), as evidenced by struggles with assertiveness and initiating conversations (Schwartz et al., 2015). Understanding these children's issues is definitely part of the solution. Striving to develop a supportive peer environment can also serve to increase cooperative skills and better engage peers who might not typically interact. Social acceptance is a basic need (Costa et al., 2017; Wesselman et al., 2017) and it is necessary for a child's healthy development. One's tolerance of another's individuality with the encouragement of uniqueness without negative repercussions, can promote positive acceptance and a network of support (Flook et al., 2015; Turner \& Cameron, 2016).

\section{Personality formation and fitting in}

From childhood through adolescence there are developmental challenges occurring within the process of personality formation and the movement toward consolidating the many roles and 
experiences one carries from certain markers within life stages. Although several personality theories view an individual with characteristics continuing to develop into later years, it is also acknowledged that certain parts of the core self, such as a child's temperament, remain steady into later childhood and over time (Friedman \& Schustack, 2016). Studies also demonstrate that some personality traits of children as early as first grade will remain constant and into adulthood (Karevold et al., 2018; Nave et al., 2010). At some point, a person's cumulative life experiences coupled with biological influences merge into personality characteristics that partially define the individual. However, a person's temperament is a component of the core self that appears as early as infancy (McAdams \& Olson, 2010) and continues to be a basic element of a person's real self.

Temperament may be viewed as a combination of stable individual traits that are consistent over time and partially relate to one's drive to behave or react in certain ways. Parents and caregivers, in their role to direct and guide, may purposefully adjust their parenting styles and interactions to adapt to a child's temperament. Though this helps to support a child and improve healthy social behaviors and interactions (Bridgett et al., 2009), their natural traits remain steady at some level, interconnected with other components of their core self. Depending on a child's temperament and their unique approach to the world, they should benefit from specific parental guidance with a "Goodness to Fit" approach to ultimately enhance compatibility between a child's temperament and the environment. Chess \& Thomas (1977) noted problems for children when temperament was not recognized, valued or accommodated, thus creating a "Poorness of Fit." Poorness of Fit may increase the likelihood of social and behavioral difficulties, especially when interacting with peers.

Personality formation and eventual individuation is an emotionally tortuous journey during one's youth, considering the opposing steady stress of assimilation among peer groups who inherently generate demands of peer pressure that challenge a child's own uniqueness. Social acceptance and peer connectedness is desirable throughout an individual's lifespan. In a 2011 review by DeWall and Bushman, they explored how human behavior has historically demonstrated the need for social acceptance and added how essential an issue this remains to this day. We as humans attempt to minimize group rejections and the negative feelings from exclusion. Here, when a group rejects an individual, it is commonly contingent upon that person's uniqueness or separateness (Bierman, 2003; King et al., 2018). Personal, nongroup, characteristics can potentiate negative feedback from the group system due to one's own individuality, as defined by such things as unique behaviors, independent thoughts or personal views and opinions. Children experience peer judgments through rejection or direct ridicule, simply based on a youth's external presentation with such things as their clothing, hairstyle, physical weight, disabilities, social skills, athleticism or physical awkwardness. Yet, all human beings are distinct, unique individuals and within us exists an inner core self, wanting human connection for social acceptance (Chiffriller et al., 2015; DeWall \& Bushman, 2011; Molden et al., 2009).

\section{Conformity and the average population}

Children typically gain knowledge of what is socially acceptable through their observations of adult models from a young age (Gergely et al., 2002; Schwier et al., 2006). They are keen to understand information presented by adults (Haun \& Tomasello, 2011) and discern the adults' motivations, social context and authority. Conformity issues, such as changing an opinion or behavior based on peer pressure, is also studied among school age children (Kim et al., 2016). Related to conformity with adults, their compliance with peer norms may be influenced by fear or punishment from the group (Thornberg, 2011). Children feel the pressures of fitting in or getting along with others in socially acceptable ways. For these youngsters, avoidance of peer shaming, teasing or ridicule can produce an almost reflexive adjustment to minimize possible embarrassment and being known as someone odd or different who is prevented from joining the group. Social exclusion and peer isolation are common consequences for not appearing to conform to social norms (Cranham \& Carroll, 2003).

Harassment and bullying are also significant components of intolerance of diversity among school children (MacDonald \& Swart, 2004). Some adolescents may suffer mental health consequences with perceived ethnic and racial discrimination (Benner et al., 2018) with symptoms related to depression, psychological distress, lower self esteem, decreased academic achievement and motivation, increased risky sexual behavior and substance use. Seeking to join peers may be an option to minimize negative feelings associated with ostracization, but this may ultimately impact an individual's sense of self due to presenting an ingenuine self. When it is a conscious decision to join group norms, there is a likely feeling of control with the choice to remain with 
the group; however, one's loss of individuality is a cost that may create symptoms of anxiety and depression. For others, it may be more of an automatic or reflexive, subconscious acceptance of group norms. Whether or not this decision is conscious, it can impact an individual's self esteem since they may have abandoned certain beliefs or values to fit in. When the core self is incongruent with the group ideal, there are usually higher risks for negative emotional reactions (Rogers, 1959) which can lead to depression and anxiety.

\section{Conformity and the challenged population}

There is extensive empirical evidence that children with an EBD or LD differ in terms of behavior and personality features from normally achieving children (Shechtman \& Pastor, 2005). Students with such disabilities may have limited participation in social activities and have fewer friendships through school (Brooks et al., 2015). When these children try to conform with peer norms to minimize threats of bullying or rejection, they may essentially sacrifice elements of their individuality as a means of decreasing victimization. School based programs supporting children who struggle with peer relationships or social problems seek to lessen bullying and alienation while developing better social skills. Ideally, these programs serve to increase positive peer interactions that are rewarding, while participants learn cooperative interactions.

Structured classroom activities which encourage group and individual exchanges help students develop social skills with peer support (Rose \& Monda-Amaya, 2012) while teachers can utilize cooperative group experiences to facilitate learning and validate students acquiring age appropriate peer interactions. One such example is a peer-mediated intervention approach used to increase social interaction among student peers. Simpson \& Bui (2017) discuss their approach when working with autism spectrum disorder (ASD) students and those without disabilities through shared reading activities. This approach promotes social interactions by teaching students to "stay with", "read with" and "talk with" members of their peer reading group to help ASD students increase opportunities to engage peers and practice social skills through group activities in and out of the classroom. In another study, Leigers et al. (2017) explored peer support arrangements in school as well as peer networks taking place outside the school. The focus was to aid students in building connections with a broader range of peers, develop socialization skills and acquire new friendships. Overall, benefits were found for students with severe disabilities as well as new friendships developed for peers without disabilities. The advantages of this cooperative program may benefit other students who struggle to fit in along with their network of peers. Lastly, an example of an intervention with positive results is peer tutoring (Okilwa \& Shelby, 2010), however it has limitations for improved socialization outcomes. Socially, it may be more beneficial to provide multiple tutors to a student rather than one, but whether there are positive effects for the development of friendships remains unclear (Hochman et al., 2015). Overall, social interactions among students are beneficial to developmental growth (Berndt, 2002), and peer friendships can lead to feeling self assured with a sense of belonging (Vaquera \& Kao, 2008).

\section{Creating a positive classroom community}

In the classroom, students need to feel valued and accepted while teacher's carry the responsibility to support constructive, positive communication among students. Open and free classroom communication helps validate feelings of acceptance among peers. Children can be encouraged to verbalize thoughts and opinions within a learning environment through the guidance and orchestration of their teacher. Creating an Adlerian-Dreikursian approach toward a democratic classroom environment helps children build self esteem and feel they belong to the group (Soheili et al., 2015). This less authoritarian model empowers students by having regular involvement in the decision making process with such things as classroom rules, student roles and the responsibilities toward the class's collective goals. It also aids the child with belonging and improving self esteem. This approach helps reduce student misbehavior through the teacher's use of encouragement and logical consequences instead of a behavioral reward and punishment system (Soheili et al., 2015).

Most school children want to feel they belong and are members of their peer group (Vaquera $\&$ Kao, 2008). This is achieved when they experience belonging through their teacher as well as classmates, who provide them with appropriate attention, value and inclusion. When there are low feelings of belongingness, a child may subconsciously resort to mistaken goals as a means of recognition and acceptance. Teachers can see this unfold as a child's particular needs are not 
met. Based on the Adlerian-Dreikursian concept that a child's behavior or misbehavior has a purpose, Dreikurs \& Soltz (1964) identified four student goals of misbehavior:

(1) Seeking Undue Attention

(2) Gaining Power

(3) Seeking Revenge for a Perceived Injustice

(4) Avoiding Failure due to Feelings of Inadequacy

The teacher's awareness of student mistaken goals can prompt interventions meant to guide a child away from misbehaviors used to artificially attain unmet needs. When teachers recognize students' real needs, they may redirect them through encouragement and supportive directives, thus moving them toward positive behavior with peer related cooperativeness. This ultimately leads them to gaining improved peer relationships, acceptance and feeling that they belong to their class.

Examples of unmet needs might include low feelings of value, lack of recognition, disrespect, feelings of being misunderstood or unsupported. If a teacher can recognize a child's real needs and what they are trying to communicate through misbehavior, they can support the child and redirect their behavior in a more appropriate manner. Much of this redirection essentially encourages a child to behave more cooperatively among peers as well as supporting their individual needs (Soheili et al., 2015). Movement toward social acceptance should emerge as peers learn to recognize each other's strengths and unique individuality (Capodieci et al., 2019). The classroom environment becomes less competitive and more cooperative, with each student belonging to the group and feeling valued, carrying a role with responsibility.

From the humanistic perspective, students' have basic psychological needs such as competence, relatedness and autonomy (Nie \& Lau, 2009). These are important needs when providing a cooperative learning environment and fostering a sense of belongingness. Such humanistic attention has benefits for non-academic outcomes such as improving self-esteem and developing positive relationships among peers (Hart, 2010; Slavin, 1987) regardless of whether or not group rewards are present. The inclusion of a behavioral system appears to have benefits when groups are measured solely on achievement while the humanistic approach places more emphasis on improving peer communication and interactions.

A humanistic group process, when compared to a cooperative classroom model, has common key features that teachers may use to support a student's ability to join with peers in a cooperative classroom/group experience. According to O'Hanlon \& Ferriter (1996), humanistic groups carry a wide range of interactions that evoke various responses from its members. They discuss themes related to the group process that include progress toward a status of equality, feeling part of and belonging, experiencing the self as responsive and capable of change and increasing feelings of self worth. Teachers may ultimately guide these themes to help students experience their potential for growth and development.

\section{Cooperative learning with peer acceptance}

Cooperative learning environments promote mutual respect, group cohesion and ultimately group successes. Children become more attentive toward their peers, with individuals carrying important roles and responsibilities while supporting the individuals within their team. Teachers may enhance positive outcomes by increasing peer alliances while reducing peer rejection in the classroom (Mikami et al., 2005).

According to Johnson \& Johnson (2008) the benefits of cooperative learning include increased achievement and productivity as well as providing a more caring environment that supports better social skills and self esteem. Cooperative learning programs that include children with both mild intellectual disabilities and without disabilities, demonstrate improved social acceptance among peers (Garrote et al., 2017). Cooperative classroom activities have shown to help develop healthier peer relationships as indicated on ratings of children without disabilities for their LD and EBD classmates with improvements in peer acceptance, popularity and social distance (Piercy et al., 2002). Positive peer ratings are also shown in higher frequency with cooperative learning experiences when compared to competitive learning situations for both types of students (Putnam et al., 1996; Wentzel \& Watkins, 2002). Cooperative learning approaches bring student groups together, working toward common goals within the classroom environment. It is a collaborative learning process emphasizing team spirit instead of individual competition with positive interdependence as its goal.

Though there are several engaging cooperative learning options for teachers to implement in their classrooms, a variation to Rudolf Dreikurs' democratic family council meeting may serve as an effective shared student experience. Here, a new approach to cooperative learning in the classroom is proposed. It is influenced by the Individual Psychology model of Alfred Adler 
along with the expanded educational approach that was further developed by Rudolf Dreikurs. Research identifies successes in cooperative learning that are best practices with evidence based research (Abramczyk \& Jurkowski, 2020). These studies also include social aspects of various negative peer relationships as well as the need for peer acceptance and improved feelings of belongingness. Peer participation in student councils is determined to be beneficial in terms of personal effects such as life skills, self esteem, developing democratic skills and improving peer relationships (Griebler \& Nowak, 2012). Characteristics of successful student councils include such things as council composition, election procedures, positions, frequency and timing of meetings, decision making and a supportive school context and training from teachers/staff. The concept of merging cooperative learning with a structured Adlerian-Dreikursian approach to a democratic classroom environment is presented below in a student council format. Steps related to the management and joining of all these concepts are listed and summarized in Table 1.

Table 1 Summary guidelines of democratic student council meeting

\begin{tabular}{ll}
\hline Guideline & Description \\
\hline Format & Teacher instructs on the process, expectations and how meetings will be run \\
When & Meeting days and times are consistent \\
Time Limits & Start and end times are established \\
Participation & All students are included in the group \\
Setting-Up & Students place their seats or desks in a circle for visible communication with all \\
& other peers \\
Minutes & Recording is simplified and formatted for easy documentation, (it can include \\
& dates, student absences, topics of discussion and majority outcomes) \\
Records & Minutes are maintained in a class binder \\
Student Roles & New chairperson and recording secretary rotated to different students each meet- \\
& ing; all other students are active participants \\
Teacher Role & Teachers are simply members of the group but may guide or intervene if necessary \\
General Rule & Everyone has a right to be heard; they may share a problem or offer feedback \\
Group Goal & The group seeks a solution to a classroom need or presented problem \\
Decisions & The majority opinion is upheld \\
Acceptance & No further discussion is made until the next meeting \\
Follow-Up & Openness to change solutions that stop working or are not beneficial \\
\hline
\end{tabular}

\section{Democratic student council as cooperative learning}

A democratic student council (DSC) can provide benefits for the teacher, classroom and individual student, as it is a cooperative, collaborative meeting that includes students, where problems are discussed and solutions found. The important objective is for all students to feel acceptance and belonging to their classroom community. Teachers promote the concept that all students have a voice without peer judgement or negative feedback. The environment is supportive and peers are encouraged to listen and respond to each other. This form of peer acceptance increases a child's sense of belonging (Capodieci et al., 2019). A democratic classroom environment helps students build self confidence and self esteem (Johnson \& Johnson, 2008). Students can experience freedom when sharing personal thoughts and ideas with an intention of helping each other. They are involved with the classroom group's decision making which encompasses roles, rules and unique goals related to everyone.

Teachers may include a DSC within the normal curriculum of the students' week and build it in as a routine. Choosing the appropriate time to set aside for this activity is imperative and must be consistent. It is a time when all students can participate without disruptions or change. For example, if all students remain in the home room on Monday mornings without outside interruptions for activities or special education needs, then setting this as the consistent meeting time is reasonable. Also, maintaining the expectation that all participants agree to meetings starting and ending on time, should be accepted as well. The DSC format is taught by the teacher, but is eventually handed over to the students to manage. Only difficult situations with occasional guidance require teacher intervention, but the teacher is generally included as simply a part of the group. Students' desks or chairs are placed in a circle and the role of the chairperson and the recording secretary is rotated to a different student each meeting. Meetings may be set for thirty minutes or longer, but this depends on the students' grade level and ability to maintain appropriate attention for a sustained period of time. Each student is entitled to bring up a problem and everyone has a right to offer feedback. No students are permitted to dominate meetings but every student's comments or ideas may be shared. Collaboratively, the DSC seeks solutions to problems with the majority opinion upheld. After the close of a meeting, 
group decisions are implemented with no further discussion allowed until the next meeting. If a decision from the previous meeting was not experienced as beneficial, a new solution may be explored. The power of a successful DSC comes from the motivation of students approaching issues and problems as a group, working collaboratively for resolution of concerns with mutual respect, responsibility and equality.

The cooperative learning environment helps students get along and support each other. With a DSC, ideas can be expressed freely among peers while the group collaboratively works to solve classroom issues and problems. Discussions are open and the communication of ideas is encouraged. A student has the opportunity to share individual suggestions while classmates may experience support and success with their contributions. In this system, the team approach helps students explore various modes of problem solving with a greater emphasis placed on social skills and building healthy relationships through teamwork (Abramczyk \& Jurkowski, 2020).

\section{Conclusion}

Cooperative learning through a DSC model focuses on inclusion for all students. Ultimately, it reinforces that peers are not disapproving or critical and that the classroom is an atmosphere where students comfortably and safely express themselves (Van Ryzin \& Roseth, 2018). Some children with LDs or EBDs have difficulty fitting in and assimilating with their peer groups. Other children, due to unique thinking or uncommon behaviors, may also experience problems connecting with peers. While some children strive to gain acceptance and belongingness, others may misbehave through mistaken goals to receive attention, value and inclusion at school. Teachers can support the real needs of these children by redirecting them toward responsibility and equality (Hayley \& Harrington, 2019). Teachers may also guide students with the purpose of preventing rejection or avoidance of peers who present as unique and different. For these children, acceptance of the self is as important as acceptance of others. Each person, being unique and one of a kind, has a distinct set of personality traits. Children who can be themselves should experience a more positive self concept. A supportive learning environment can help these children respect their own uniqueness and develop naturally as they are.

\section{Ethics}

This article does not contain any studies with human participants or animals performed by the author.

\section{References}

Abramczyk, A. \& Jurkowski, S. (2020). Cooperative learning as an evidence-based teaching strategy: What teachers know, believe, and how they use it. Journal of Education forTeaching, 46(3), 296-308. https://doi.org/10.1080/02607476.2020.1733402

Benner, A. D., Wang, Y., Shen, Y., Boyle, A. E., Polk, R., \& Cheng, Y. (2018). Racial/ethnic discrimination and well-being during adolescence: A meta-analytic review. American Psychologist, 73(7), $855-883$. https://doi.org/10.1037/amp0000204

Berndt, T. J. (2002). Friendship quality and social development. Current Directions in Psychological Science, 11, 7-10. https://doi.org/10.1111/1467-8721.00157

Bierman, K. L. (2003). Peer rejection: Developmental processes and intervention strategies. New York: The Guilford Press.

Bridgett, D. J., Gartstein, M. A., Putnam, S. P., McKay, T., Iddins, E., Robertson, C., Ramsay, \& K., Ritmueller, A. (2009). Maternal and contextualinfluences and the effect of temperament development during infancy on parenting in toddlerhood. Infant Behavior \& Development, 32(1), 103-116. https://doi.org/10.1016/j.infbeh.2008.10.007

Brooks, B. A., Floyd, F., Robins, D. L., \& Chan, W. Y. (2015).Extracurricular activities and the development of social skills in children with intellectual and specific learning disabilities. Journal of Intellectual Disability Research, 59(7), 678-687. https://doi.org/10.1111/jir.12171

Capodieci, A., Rivetti, T., \& Cornoldi, C. (2019). A cooperative learning classroom intervention for increasing peer's acceptance of children with ADHD. Journal of Attention Disorders, 23(3), 282-292. https://doi.org/10.1177/1087054716666952

Chess, S. \& Thomas A. (1977). Temperamental individuality from childhood to adolescence. Journal of the American Academy of Child and Adolescent Psychiatry, 16(2), 218-226. https://doi.org/10.1016/S0002-7138(09)60038-8 
Chiffriller, S. H., Kangos, K. A., \& Milone, L. (2015). What elementary students experience outside of the classroom: Children's responses to social exclusion. Journal of School Counseling, 13(1), 1-25.

Cranham J., \& Carroll A. (2003). Dynamics within the bully/victim paradigm: A qualitative analysis. Educational Psychology in Practice, 19, 113-132. https://doi.org/10.1080/02667360303235

Costa, U. M., Brauchle, G., \& Kennedy-Behr, A. (2017). Collaborative goal setting with and for children as part of therapeutic intervention. Disability and Rehabilitation, 39(16), 1589-1600. https://doi.org/10.1080/09638288.2016.1202334

DeWall, N. \& Bushman, B.J. (2011). Social acceptance and rejection: The sweet and the bitter. Current Directions in Psychological Science, 20(4), 256-260. https://doi.org/10.1177/0963721411417545

Dreikurs, R. \& Soltz, V. (1964). Children: The challenge. New York: Hawthorn Books.

Elliott, R. (2001). The effectiveness of humanistic therapies: A meta-analysis. In D. J. Cain \& J. Seeman (Eds.), Humanistic psychotherapies: Handbook of research and practice (pp. 55-82). Washington, DC: American Psychological Association.

Flook, L., Goldberg, S. B., Pinger, L., \& Davidson, R. J. (2015). Promoting prosocial behavior and self-regulatory skills in preschool children through a mindfulness-based kindness curriculum. Developmental Psychology, 51(1), 44-51. https://doi.org/10.1037/a0038256

Friedman, H. S. \& Schustack, M. W. (2016). Personality: Classic Theories and Modern Research. USA: Pearson Education.

Garrote, A., Dessemontet, R. S., \& Opitz, E. M. (2017). Facilitating the social participation of pupils with special educational needs in mainstream schools: A review of school-based interventions. Educational Research Review, 20, 12-23 https://doi.org/10.1016/j.edurev.2016.11.001

Gergely, G., Bekkering, H., \& Kiraly, I. (2002). Rational imitation in preverbal infants. Nature, 415 , 755-755. https://doi.org/10.1038/415755a

Glew, G., Rivara, F., \& Feudtner, C. (2000). Bullying: Children hurting children. Pediatrics in Review, 21, 183-190. https://doi.org/10.1542/pir.21-6-183

Griebler, U. \& Nowak, P. (2012). Student councils: A tool for health promoting schools? Characteristics and effects. Health Education, 112, 105-132. https://doi.org/10.1108/09654281211203402

Hart, R. (2010). Classroom behavior management: Educational psychologists' view on effective practice. Emotional and Behavioural Difficulties, 15(4), 353-371. https://doi.org/10.1080/13632752.2010.523257

Haun, D. B. M. \& Tomasello, M. (2011). Conformity to peer pressure in preschool children. Child Development, 82(6), 1759-1767. https://doi.org/10.1111/j.1467-8624.2011.01666.x

Hayley, F. \& Harrington, I. (2019). A review into effective classroom management and strategies for student engagement: Teacher and student roles in today's classrooms. Journal of Education and Training Studies, 7(12), 1-12. https://doi.org/10.11114/jets.v7i12.4491

Hochman, J. M., Carter, E. W., Bottema-Beutel, K., Harvey, M. N., \& Gustafson, J. R. (2015). Efficacy of peer networks to increase social connections among high school students with and without autism spectrum disorder. Exceptional Children, 82, 96-116. https://doi.org/10.1177/0014402915585482

Johnson R. T., \& Johnson, D. W. (2008). Active learning: Cooperation in the classroom. The Annual Report of Educational Psychology in Japan, 47, 29-30. https://doi.org/10.5926/arepj1962.47.0_29

Karevold, E. B., Mathiesen, K. S., Bårdstu, S., \& Sanson, A. V. (2018). Temperament and personality development in children and adolescents. In K. S. Mathiesen, A. V. Sanson, \& E. B. Karevold (Eds.), Tracking opportunities and problems from infancy to adulthood: 20 years with the TOPP study (pp 39-54). Boston, MA, US: Hogrefe Publishing. https://doi.org/10.1027/00543-000

Kim, E. B., Chuansheng, C., Smetana, J. G., \& Greenberger, E. (2016). Does children's moral compass waver under social pressure? Using the conformity paradigm to test preschoolers' moral and socialconventional judgments. Journal of Experimental Child Psychology, 150, 241-251. https://doi.org/10.1016/j.jecp.2016.06.006

King, K. M., McLaughlin, K. A., Silk, J., \& Monahan, K. C. (2018). Peer effects on self-regulation in adolescence depend on the nature and quality of the peer interaction. Development and Psychopathology, 30(4), 1389-1401. https://doi.org/10.1017/S0954579417001560

Leigers, K., Kleinert, H., \& Carter, E. W. (2017). "I never truly thought about them having friends": Equipping schools to foster peer relationships. Rural Special Education Quarterly, 36, 73-83. https://doi.org/10.1177/8756870517707711

MacDonald, H., \& Swart, E. (2004). The culture of bullying at a primary school. Education as Change, $8(2), 33-55$ https://doi.org/10.1080/16823200409487090 
McAdams, D., \& Olson, B (2010). Personality development: Continuity and change over the life course. Annual Review of Psychology, 61, 517-542.

https://doi.org/10.1146/annurev.psych.093008.100507

Mikami, A. Y, Boucher, M. A. \& Humphreys, K. (2005). Prevention of peer rejection through a classroomlevel intervention in middle school. Journal of Primary Prevention, 26(1), 5-23. https://doi.org/10.1007/s10935-004-0988-7

Molden, D. C., Lucas, G. M., Gardner, W. L., Dean, K., \& Knowles, M. L. (2009). Motivations for prevention or promotion following social exclusion: Being rejected versus being ignored. Journal of Personality and Social Psychology, 96(2), 415- 431. https://doi.org/10.1037/a0012958

Nave, C., Sherman, R., Funder,D., Hampson, S., \& Goldberg, L. (2010). On the contextual independence of personality: Teachers' assessments predict directly observed behavior after forty decades. Social Psychological \& Personality Science, 1(4), 327-334. https://doi.org/10.1177/1948550610370717

Nie Y., \& Lau, S. (2009). Complementary roles of care and behavioral control in classroom management: The self-determination theory perspective. Contemporary Educational Psychology, 34, 185-94. https://doi.org/10.1016/j.cedpsych.2009.03.001

O'Hanlon, J. \& Ferriter, K. (1996). Humanistic and integrative group therapy. Inside Out: The Irish Journal for Humanistic and Integrative Psychotherapy, 25, 2.

Okilwa, N. S. A., \& Shelby, L. (2010). The effects of peer tutoring on academic performance of students with disabilities in grades 6 through 12: A synthesis of the literature. Remedial and Special Education, $31,450-463$. https://doi.org/10.1177/0741932509355991

Piercy, M., Wilton, K. \& Townsend, M. (2002). Promoting the social acceptance of young children with moderate-severe intellectual disabilities using cooperative-learning techniques. American Journal of Mental Retardation, 107(5), 352-360.

https://doi.org/10.1352/0895-8017(2002)107〈0352:PTSAOY $\rangle 2.0 . C O ; 2$

Putnam, J., Markovchick, K., Johnson, D. \& Johnson, R. (1996). Cooperative learning and peer acceptance of students with learning disabilities. The Journal of Social Psychology,136(6), 741-752. https://doi.org/10.1080/00224545.1996.9712250

Rogers, C. (1959). A theory of therapy, personality and interpersonal relationships as developed in the client-centered framework. In (ed.) S. Koch, Psychology: A study of a science. Vol. 3: Formulations of the person and the social context. New York: McGraw Hill.

Rose, C. A., \& Monda-Amaya, L. E. (2012). Bullying and victimization among students with disabilities: Effective strategies for classroom teachers. Intervention in School and Clinic, 48(2), 99-107. https://doi.org/10.1177/1053451211430119

Rossetti, Z. \& Keenan, J. (2017). The nature of friendship between students with and without severe disabilities. Remedial and Special Education. Prepublished April 4, 2017. https://doi.org/10.1177/0741932517703713

Schwartz, D., Lansford, J. E., Dodge, K. A., Pettit, G. S., \& Bates, J. E. (2015). Peer victimization during middle childhood as a lead indicator of internalizing problems and diagnostic outcomes in late adolescence. Journal of Clinical Child and Adolescent Psychology, 44(3), 393-404. https://doi.org/10.1080/15374416.2014.881293

Schwier, C., van Maanen, C., Carpenter, M. \& Tomasello, M. (2006). Rational imitation in 12-month-old infants. Infancy, 10, 303-311. https://doi.org/10.1207/s15327078in1003_6

Shechtman, Z. \& Pastor, R. (2005). Cognitive-behavioral and humanistic group treatment for children with learning disabilities: A comparison of outcomes and process. Journal of Counseling Psychology, 52(3), 322-336. https://doi.org/10.1037/0022-0167.52.3.322

Simpson, L. \& Bui Y. (2017). Reading Buddies: A strategy to increase peer interaction in students with autism. Intervention in School and Clinic, 53(1), 44-49. https://doi.org/10.1177/1053451217692570

Slavin, R. (1987). Cooperative learning: Where behavioural and humanistic approaches to classroom management meet. The Elementary School Journal, 88(1), 29-37. https://doi.org/10.1086/461521

Smokowski, P. R., \& Kopasz, K. H. (2005). Bullying in school: An overview of types, effects, family charactersitics, and intervention strategies. Children \& Schools, 27(2), 101-110. https://doi.org/10.1093/cs/27.2.101

Soheili, F., Alizadeh, H., Murphy, J. M., Hossein, S. B., \& Ferguson, E. D. (2015). Teachers as leaders: The impact of Adler-Dreikurs classroom management techniques on students' perceptions of the classroom environment and on academic achievement. The Journal of Individual Psychology, 71(4), 440-461. https://doi.org/10.1353/jip.2015.0037

Thornberg, R. (2011). "She's weird"-the social construction of bullying in school: A review of qualitative research. Children and Society, 25(4), 258-267. https://doi.org/10.1111/j.1099-0860.2011.00374.x

Turner, R. N. \& Cameron, L. (2016). Confidence in contract: A new perspective on promoting crossgroup friendship among children and adolescents. Social Issues and Policy Review, 10(1), 212-246. https://doi.org/10.1111/sipr.12023 
Van Ryzin, M. J. \& Roseth, C. J. (2018). Cooperative learning in middle school: A means to improve peer relations and reduce victimization, bullying, and related outcomes. Journal of Educational Psychology, $110(8), 1192-1201$. https://doi.org/10.1037/edu0000265

Vaquera, E., \& Kao, G. (2008). Do you like me as much as I like you? Friendship reciprocity and its effects on school outcomes among adolescents. Social Science Research, 37, 55-72. https://doi.org/10.1016/j.ssresearch.2006.11.002

Wentzel, K.R. \& Watkins, D. E. (2002). Peer relationships and collaborative learning as contexts for academic enablers. School Psychology Review, 31(3), 366-377. https://doi.org/10.1080/02796015.2002.12086161

Wesselman, E. D., Wirth, J. H., \& Bernstein, M. J. (2017). Expectations of social inclusion and exclusion. Frontiers in Psychology, 8, 112.

https://doi.org/10.3389/fpsyg.2017.00112 